\title{
Congenital plaque-like glomangioma: report of two cases*
}

\author{
Nivea Godinho Alves de Souza ${ }^{1}$ \\ Gisele Alborghetti $\mathrm{Nai}^{2}$
}

\author{
Gláucia Ferreira Wedy ${ }^{1}$ \\ Marilda Aparecida Milanez Morgado de Abreu ${ }^{3,4}$
}

DOI: http:/ /dx.doi.org/10.1590/abd1806-4841.20175766

\begin{abstract}
Glomus tumors are rare hamartomas that originate from the glomus body. These tumors can be divided into solitary and multiple, the latter also known as glomangioma. We report the case of two patients with a rare variety of glomangioma called congenital plaque-like glomangioma. It presents as numerous red to bluish compressible papules, that increase in size in proportion with the weight and height growth of the child. Diagnostic confirmation is with histopathology and the treatment is surgical.
\end{abstract}

Keywords: Congenital abnormalities; Hamartoma; Glomus tumor

\section{INTRODUCTION}

Glomus tumors are rare hamartomas that arise from a neuromyoarterial structure known as glomus body. ${ }^{1-4}$ They represent less than $2 \%$ of soft skin tumors. They usually occur on areas that are rich in glomus bodies such as distal extremities of digits, in particular in the subungual region, palms, wrists, forearms and feet. Less frequent locations include deep soft tissue, nerves, bones, penis, stomach and small bowel. ${ }^{1,2}$ They are divided into solitary, that correspond to $90 \%$ of the reported cases, and multiple, known as glomangiomas. ${ }^{2-7}$

We present the case of two female patients that developed blue-purple papules and nodules, forming plaques, in multiple locations during childhood. Both had painful lesions. The importance of the report is due to the rarity of the condition, which is underdiagnosed because it is not well known.

\section{CASE REPORT}

Case 1

A white 36-year-old female patient complained of multiple lesions that appeared during childhood and were progressively enlarging in number and in size with age. According to the patient, the lesions were painful with minimal trauma. On physical examination, there were blue-purple papules and nodules, from a few millimeters to almost $2 \mathrm{~cm}$ in size, grouped in plaques of $10 \mathrm{~cm}$ in average on the epigastric and right inguinocrural region. On the right hemithorax, the lesions had a zosteriform pattern and, on the upper limbs, the lesions were sparse (Figures 1 and 2). She denied similar cases in the family. Histopathology revealed multiple dilated vessels in the papillary dermis, whose walls had more than one layer of small, round, uniform cells with round and central nuclei and eosinophilic cytoplasm, characterizing glomus cells (Figure 3).

Work submitted on 06.03.2016

Approved by the Advisory Board and accepted for publication on 17.08.2016

* Study conducted at Hospital Regional de Presidente Prudente - Universidade do Oeste Paulista (HRPP-Unoeste) - Presidente Prudente (SP), Brazil.

Financial support: None

Conflict of interest: None

1 Post-graduation Program in Dermatology, Hospital Regional de Presidente Prudente - Universidade do Oeste Paulista (HRPP- Unoeste) - Presidente Prudente (SP), Brazil.

Department of Pathology, Faculdade de Medicina da Universidade do Oeste Paulista (Unoeste) - Presidente Prudente (SP), Brazil.

Department of Dermatology, Faculdade de Medicina da Universidade do Oeste Paulista (Unoeste) - Presidente Prudente (SP), Brazil.

4 Department of Dermatology, Hospital Regional de Presidente Prudente “Dr. Domingos Leonardo Cerávolo" (HRPP) - Presidente Prudente (SP), Brazil. 

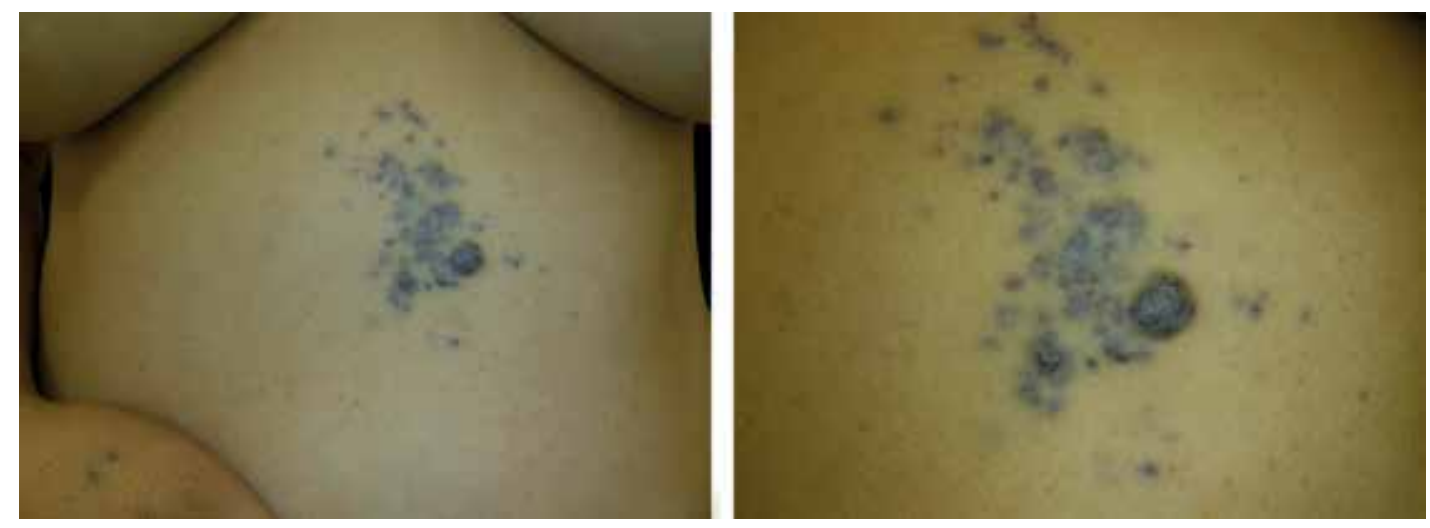

Figure 1:

Case 1: blue-purple papules and nodules from a few millimeters to almost $2 \mathrm{~cm}$, grouped in plaques of about $10 \mathrm{~cm}$ on the epigastric region
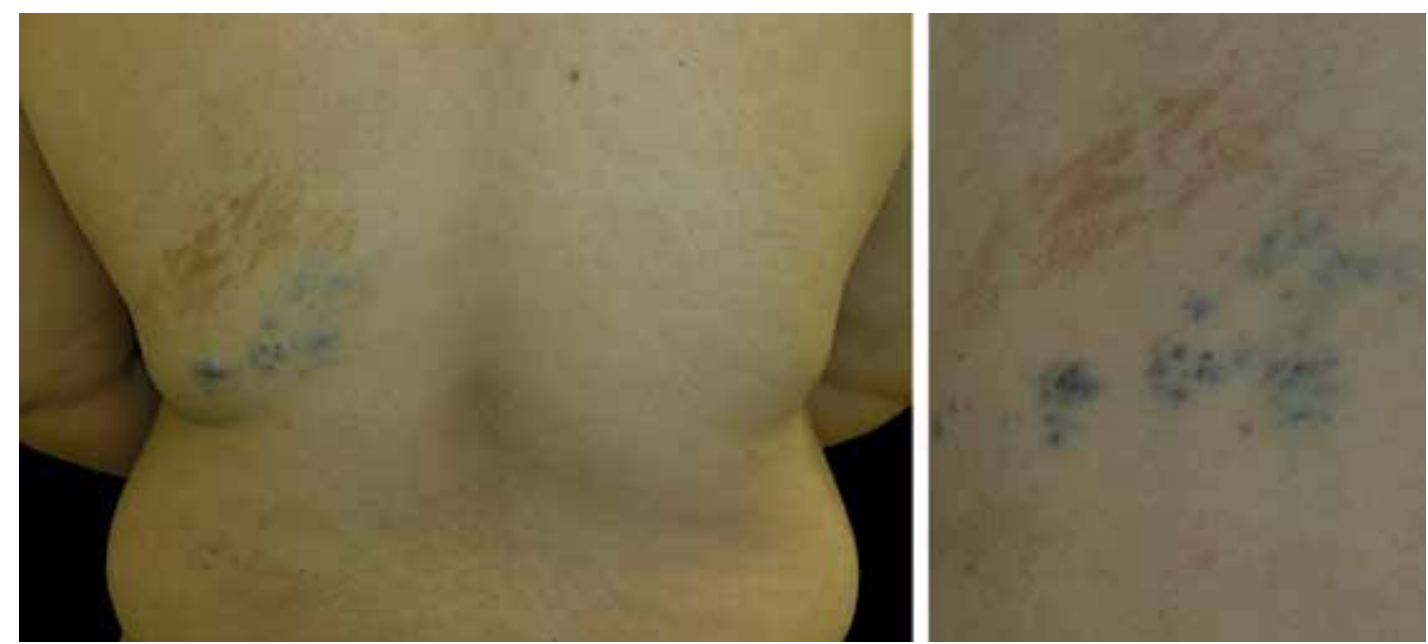

Figure 2:

Case 1: lesions on the left hemithorax in a zosteriform pattern
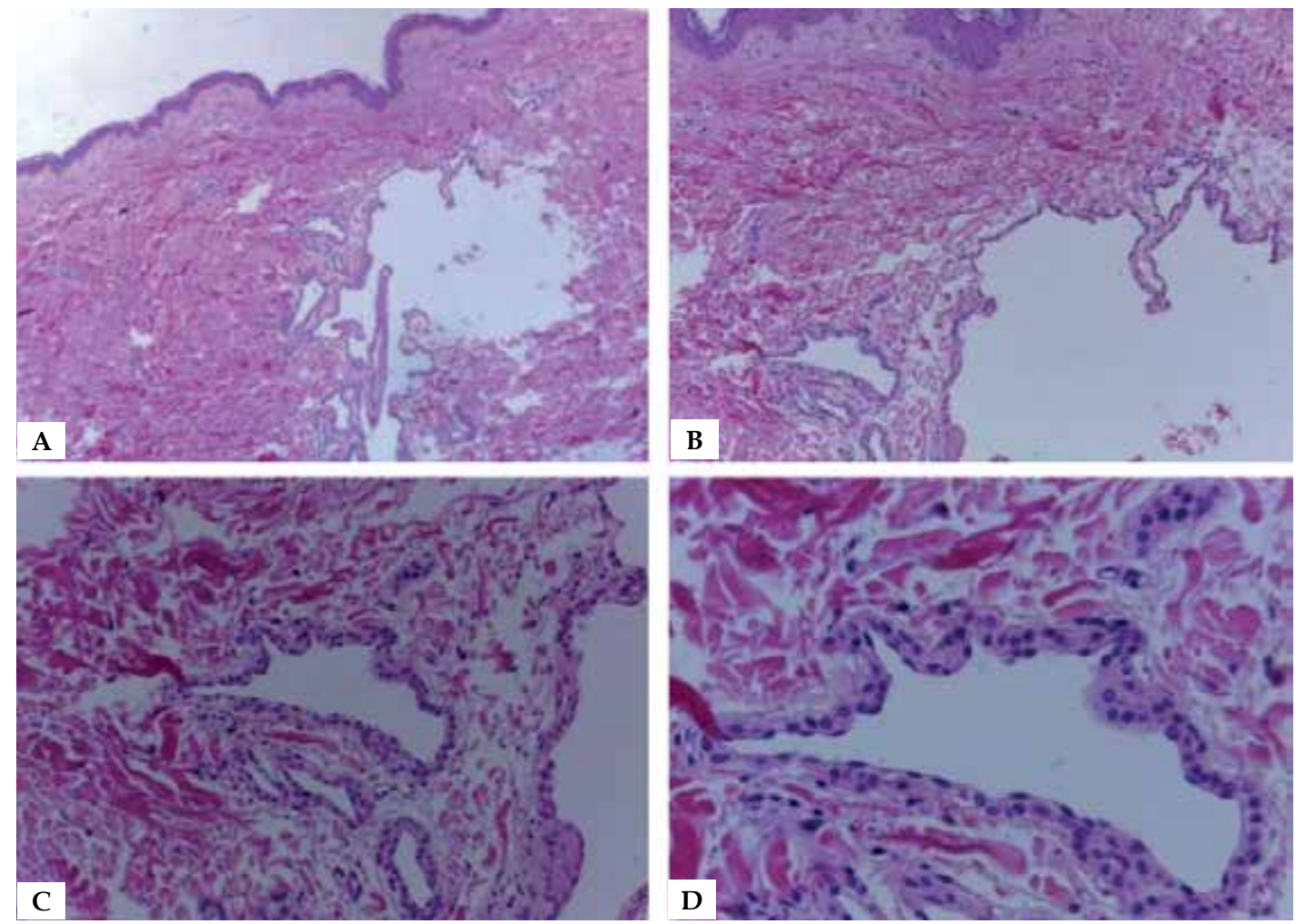

\section{Figure 3:}

Photomicroscopy of the skin. A and B: Superficial dermis with area of vascular dilatation (Hematoxylin \& eosin, X40 and X100, respectively). C: A group of multiple dilated vessels (Hematoxylin \& eosin, X200). D: Vascular wall with more than one layer of small, round, uniform cells, with central round nuclei and eosinophilic pale cytoplasm (glomus cells) (Hematoxylin \& eosin, X400) 

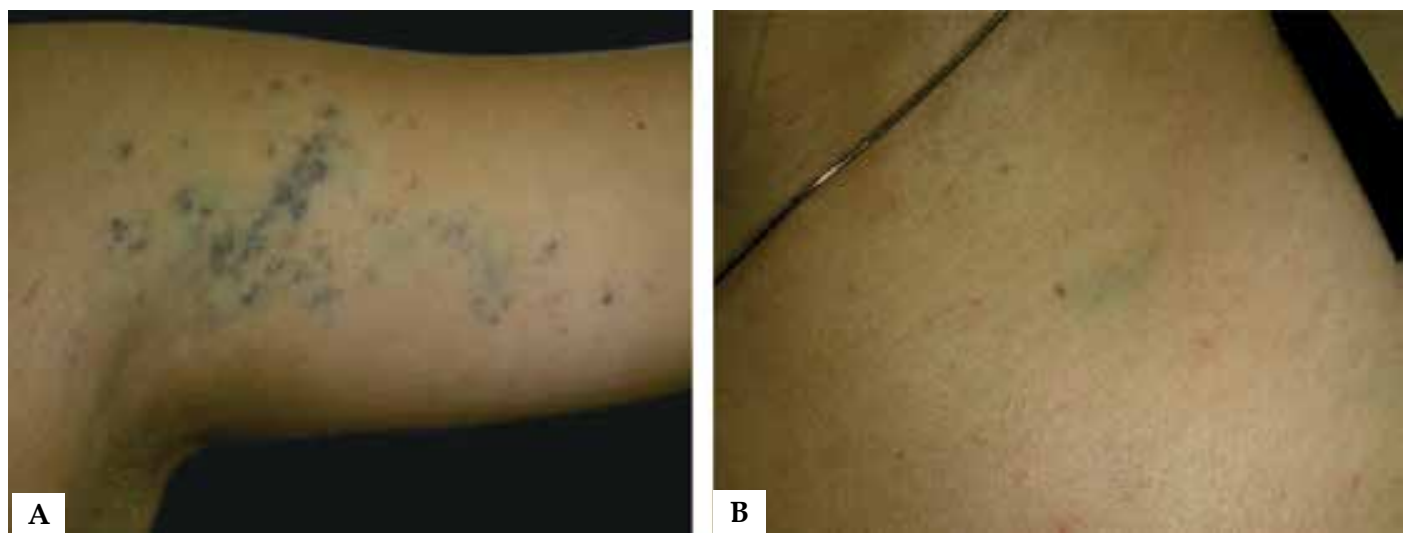

Figure 4:

Case 2: A: Telangiectasias, blue-purple small grouped papules forming plaques of $5 \mathrm{~cm}$ on the medial aspect of the left arm.

B: Blue nodule with about $2 \mathrm{~cm}$ on the left infraclavicular region
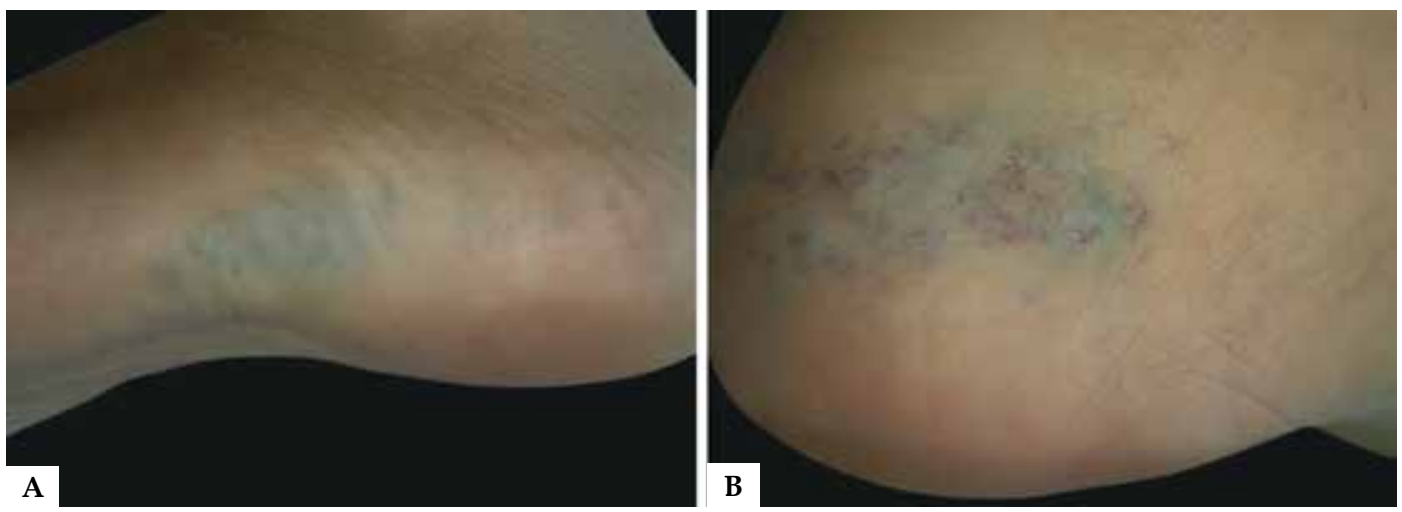

Figure 5:

Case 2: A and B: Telangiectasias, blue-purple grouped papules of a few millimeters in diameter forming plaques on the lateral aspect of the left foot and left ankle

In face of the clinical history, presentation of lesions and histopathology, the rarer type of glomangioma was diagnosed, the congenital plaque-like.

\section{Case 2}

A white 17-year-old female patient complained of lesions since birth that increased over time. There were telangiectasias, blue-purple papules with a few millimeters in diameter, grouped in plaques of about $5 \mathrm{~cm}$ on the medial aspect of the left arm and lateral aspect of the left foot and left ankle. There was also a blue 2-cm nodule on the left infraclavicular region (Figures 4 and 5). She reported spontaneous pain in the lesions of the foot, and pain related to trauma in the other lesions. In the premenstrual period, the pain worsened and made walking difficult. She denied similar cases in the family.

\section{DISCUSSION}

Solitary glomus tumor corresponds to a single, small, red, or purple papule or nodule, between 2 and $10 \mathrm{~mm} \cdot{ }^{1,3,6}$ All patients experience pain. ${ }^{2}$ Cold and pressure can trigger incapacitating pain. ${ }^{1}$ There is no gender predilection and it occurs sporadically in adults between the third and fourth decade of life. ${ }^{1,3,6,7}$ Familial cases are rare, with less than 20 cases reported in the literature, with autosomal dominant inheritance, reduced penetrance and variable expression. . $^{1,4,5,7,8}$

Glomangiomas appear as subtle purplish papules or nodules, that can be asymptomatic or painful. A third of the cases appear before 20 years of age, with male predominance. ${ }^{3,7}$ About $60 \%$ report at least one family member affected. ${ }^{1,7}$ In contrast, we report two female patients with no family history and spontaneous pain in one of them.

Glomus tumors and glomangiomas were initially grouped in glomuvenous malformations. With time, it was seen that glomangiomas are a distinct entity. Congenital glomangioma can have one variant, classified by Happle and Konig as segmental type II, in which the appearance of the primary lesion is followed by the appearance of multiple distal lesions..$^{9,10}$

We opted to classify glomangiomas according to the location of the lesions and to the congenital presentation. Therefore, they are subdivided into:

1. -Multiple disseminated glomangioma: corresponds to multiple papules or nodules, usually more than 10, ranging from red to blue, usually smaller than $1 \mathrm{~cm}$ and widespread. ${ }^{3}$ Familial cases are reported, demonstrating the autosomal dominant inheritance, with variable penetrance and expression.

2. -Multiple localized glomangioma, also known as regional: corresponds to multiple blue lesions, grouped on one body area, usually the leg or the arm. ${ }^{3,5}$

3. -The congenital plaque-like, described in 1990 by Landthaler et al., presents with numerous compressible red to blue papules, isolated or in plaques, measuring between $10-20 \mathrm{~cm}$. ${ }^{3,5,6}$ Pain is not common, and it can be spontaneous or triggered by trauma or changes in temperature. In our patients, the pain was triggered by trauma. One of them reported paroxysmal pain during her menses. There are cases in the literature of increased pain during pregnancy due to hormonal factors, but no evidence of a relationship with menses. ${ }^{5}$ The lesions increased proportionately to the patient's 
growth during puberty, as seen in this report. ${ }^{3}$

The diagnosis of glomangioma is a clinical one, and is confirmed by histopathology ${ }^{5}$, which will show non-encapsulated tumors, with irregular cavernous vessels, lined with polygonal, monomorphic or round glomus cells and eosinophilic cytoplasm. Immunohistochemistry is an ancillary tool for the diagnosis: glomus cells are positive for smooth muscle alpha actin, while the cells of the vascular endothelium are positive for CD34., ${ }^{2,3,5,10}$

Magnetic resonance imaging can define the extension of the disease and help plan the treatment. ${ }^{1,5}$ Laboratory tests are un-necessary, unless there is risk of platelet sequestration (multiple or extensive lesions). ${ }^{1}$

The differential diagnosis includes: blue rubber bleb nevus syndrome, venous malformations, hemangioma, pyogenic granulo$\mathrm{ma}$, spiradenoma, angiolipoma, leiomioma, intradermal nevus and malignant melanoma. ${ }^{1,4,5}$

\section{REFERENCES}

1. Dias C, Maia A, Selores M. Caso dermatológico. Nascer e crescer. 2013;22:185-6.

2. Guillaumon AT, Bosnardo CAF, de Meirelles LR. Glomangioma da artéria digital do polegar - relato de um caso. J Vasc Bras. 2012;11:320-3.

3. Munoz C, Bobadilla F, Fuenzalida H, Goldner R, Sina B. Congenital glomangioma of the breast: type 2 segmental. Int J Dermatol. 2011;50:346-9.

4. Glick SA, Markstein EA, Herreid P. Congenital glomangioma: case report and review of the world literature. Pediatr Dermatol. 1995;12:242-4.

5. Carvalho VO, Taniguchi K, Giraldi S, Bertogna J, Marinoni LP, Fillus JN, et al. Congenital plaquelike glomus tumor in a child. Pediatr Dermatol. 2001;18:223-6.

6. Souza VL, Fraga JCS, Gaburri D, Valverde RV, Gamona A. Caso para diagnóstico. An Bras Dermatol. 2006;81:384-6.

7. Solovan C, Chiticariu E, Beinsan D, Zurac S, Baderca F. Multiple disseminated glomuvenous malformations: do we know enough? Rom J Morphol Embryol. 2012:53:1077-80.
The treatment will be symptomatic. ${ }^{7}$ Surgery is the treatment of choice for isolated and painful glomus tumors. Recurrence rate after surgery is of $10 \% .^{2,5}$ In the large lesions, sclerotherapy or laser ablation can provide some benefit. ${ }^{2,3,5,6}$ The lesions do not involute spontaneously, but the prognosis is good in the majority of cases, with rare cases of malignant transformation. ${ }^{1,2,5}$

We reported two patients with congenital plaque-like glomangioma. The diagnosis was suspected by the clinical aspect of the lesions. The suspicion was reinforced by the fact that the lesions appeared right after birth, with slow growth. The confirmation was with histopathology.
8. Blume-Peytavi U, Adler YD, Geilen CC, Ahmad W, Christiano A, Goerdt S. Multiple familial cutaneous glomangioma: a pedigree of 4 generations and critical analysis of histologic and genetic differences of glomus tumors, J Am Acad Dermatol. 2000;42:633-9.

9. Happle R, König A. Type 2 segmental manifestation of multiple glomus tumors: a review and reclassification of 5 case reports. Dermatology. 1999;198:270-2.

10. Borroni RG, Grassi S, Concardi M, Puccio I, Giordano C, Agozzino M, et al. Glomuvenous malformations with smooth muscle and eccrine glands: unusual histopathologic features in a familial setting. J Cutan Pathol. 2014;41:308-15

\footnotetext{
MAILING ADDRESS:

Nivea Godinho Alves de Souza

R. José Bongiovani, 1297

Vila Liberdade

19050-680 Presidente Prudente, SP

Brazil

E-mail: nivea60@hotmail.com
}

How to cite this article: Souza NGA, Wedy GF, Nai GA, Morgado de Abreu MAM. Congenital plaque-like glomangioma: report of two cases. An Bras Dermatol. 2017;92(5 Suppl 1): 43-6. 